\title{
INTRODUCCIÓN: LAS CIENCIAS DE LA TIERRA Y LA HISTORIA DE LA GEOLOGÍA EN MÉXICO
}

\author{
José Alfredo Uribe Salas (Coord.) \\ Universidad Michoacana de San Nicolás de Hidalgo, México \\ jausalas@gmail.com
}

Recibido: 18 septiembre 2014; Aceptado: 13 julio 2015.

Cómo citar este artículo/Citation: Uribe Salas, José Alfredo (Coord.) (2015), “Introducción: Las Ciencias de la Tierra y la historia de la geología en México", Asclepio, 67 (2): p099. doi: http://dx.doi.org/10.3989/asclepio.2015.17

\section{INTRODUCTION: EARTH SCIENCES AND HISTORY OF GEOLOGY IN MEXICO}

En éste dossier se integran cuatro artículos que se presentaron y discutieron en el coloquio Geología para Historiadores, que tuvo como escenario a la Facultad de Historia de la Universidad Michoacana de San Nicolás de Hidalgo, Morelia, México, el 16 de diciembre de 2013.

El tema central de los trabajos es el estudio del interés público y privado por explorar el territorio mexicano en busca de recursos naturales que pudieran ser de utilidad para el desarrollo del país y el bien común de su población, en su etapa independiente. De manera paralela, se destaca la elaboración de un discurso local y trasnacional que buscaba sistematizar los nuevos datos geográficos, astronómicos, meteorológicos, botánicos, mineralógicos y volcánicos, en un «cuerpo de conocimiento" que transitaba de los enfoques de la Historia Natural a la Geografía y la Geología como disciplinas modernas. Los trabajos también analizan la práctica científica que desplegaron individuos, comisiones oficiales o empresas privadas en sus afanes por encontrar nuevos recursos en la corteza terrestre, ya que permite conocer a los actores involucrados, sus relaciones y redes, lo mismo que las condiciones sociales e institucionales en las que se generaban los nuevos conocimiento y su difusión más allá de las comunidades profesionales e instituciones de educación del país o del extranjero.

Los artículos tienen rasgos de originalidad en tanto que incorporan a sus estudios nuevos datos, fuentes y enfoques metodológicos, y abarcan distintos aspectos y problemas sociales, culturales y económicos del siglo XIX en México. Los títulos por sí mismos desbrozan el camino recorrido en cada uno de ellos: Historia, literatura y ciencia en la exploración a las cavernas de 
Cacahuamilpa en el siglo XIX; La investigación geológica en la Comisión Científica de México; Entender la naturaleza para crear una industria. El petróleo en la exploración de John McLeod Murphy en el istmo de Tehuantepec en 1865; y, Orígenes y fundación del Instituto Geológico de México. En su conjunto, el dossier retoma el análisis de los conceptos, líneas de investigación y las fuentes de información que los profesionales de la ciencia, nacionales y extranjeros del siglo XIX, incorporaron al estudio de la geografía, la geología, la mineralogía, la paleontología, la estratigrafía y la estadística, para entender y explicar la realidad mexicana de su tiempo. También se propone una serie de hipótesis relacionadas con el surgimiento en México de un nuevo entramado de relaciones culturales como sustento del proceso de institucionalización y profesionalización del saber geológico en México, y se plantean nuevas líneas de investigación especialmente en torno a la circulación del conocimiento, su recepción entre distintas comunidades y las relaciones de intercambio y colaboración entre diversas instituciones y países del mundo occidental.

José Alfredo Uribe Salas y Laura Valdivia Moreno abordan, desde la literatura y la ciencia, el interés que despertó en el imaginario social las cavernas de Cacahuamilpa como posible fuente de recursos naturales, como evidencia inigualable de la creación divina, como monumento de la naturaleza con gran valor estético para la recreación y el turismo o como el ámbito inmejorable para conocer los componentes físicos y químicos de los procesos de transformación de la tierra. En el siglo XIX las cavernas de Cacahuamilpa atrajeron el interés y la curiosidad de políticos, gobernantes, diplomáticos, militares, viajeros, naturalistas y científicos, y cuya visión y testimonio quedó registrado en artículos periodísticos, obras literarias, loas poéticas, ensayos y monografías con tintes políticos y científicos. Ese material se publicó en diferentes idiomas y logró posesionar a las cavernas como una de las más prominentes del globo terráqueo en el siglo XIX, y en un laboratorio de especulación e interrogantes para las ciencias de la Tierra. En el último cuarto del siglo XIX, con la cobertura institucional de la Sociedad Mexicana de Geografía y Estadística (SMGE), el Instituto Médico Nacional y el Instituto Geológico Mexicano, los naturalistas, geógrafos y geólogos lograron marcar las fronteras con la literatura hasta adquirir una identidad disciplinar propia.

Luz Fernanda Azuela hace un recorrido fundamental de los estudios geológicos realizados por distintos viajeros que recorrieron el territorio de la Nueva Es- paña y México hasta el establecimiento del Imperio de Maximiliano de Habsburgo (1864-1867) y la Commission Scientifique du Mexique (CSM) en el periodo de la intervención francesa. La autora también analiza el desconocimiento que tenían los geólogos franceses del conocimiento local y la desconfianza epistemológica sobre los alcances de algunos de ellos que integraron a sus proyectos de investigación. Esa bisagra analítica le permite profundizar en el contexto social del establecimiento de la CSM y poner en valor conceptual el estado del conocimiento sobre el que se configurarían los objetivos, metas y productos de la CSM en el estudio de la geología de México. Se abordan, desde luego, los apartes que acercó la Commission Scientifique du Mexique para el reconocimiento y estudio de la realidad geológica mexicana, las relaciones asimétricas que establecieron con las comunidades locales, y la renovación de enfoques disciplinarios, en la teoría y en la práctica científica nacional.

Francesco Gerali y Paolo Riguzzi estudian la naturaleza y los objetivos de la comisión científica estadunidense, que a mediados del siglo XIX exploró la región del istmo de Tehuantepec en un escenario internacional apremiado por ubicar el mejor derrotero para la comunicación interoceánica. Los estudios realizados reunieron una gran cantidad de información sobre la topografía, los recursos de fauna y flora, hidrográficos y geológicos de la región, y encontraron claras evidencias de recursos fósiles combustibles que podían explotarse con buenos resultados. Discuten entonces la relación entre ciencia y economía en el horizonte del interés estadounidense por localizar e incorporar recursos naturales fuera de sus fronteras a las nuevas dinámicas de la economía. Y sostienen que los informes y proyectos de explotación del hidrocarburo localizado en la región, representa «la primera combinación de exploración geográfica, medición topográfica, interpretación geológica y logística comercial del petróleo mexicano».

Lucero Morelos Rodríguez y José Omar Moncada Maya estudian el proceso de institucionalización de la geología en México con el cobijo del interés del Estado y el patrocinio de la Secretaría de Fomento, en la segunda mitad del siglo XIX. Analizan con profusión distintos esquemas de organización previos que servirían de respaldo a la creación del Instituto Geológico Nacional en 1891, como la Comisión Geológica Mexicana (1888), y la conjunción de intereses entre la comunidad científica y las autoridades de gobierno para abrir un espacio en el que se estudiara con el rigor de las ciencias de la Tierra los recursos mineros, 
hídricos y los fósiles combustibles para su explotación industrial. El estudio destaca el liderazgo de un grupo de profesionales decantados por el cultivo de las ciencias, como los ingenieros de minas Antonio del Castillo y José Guadalupe Aguilera, entre otros, en la profesionalización de la geología en México.

Los trabajos que se presentan en éste Dossier, constituyen una buena síntesis del interés que tienen los especialistas de la Historia de la Ciencia mexicana en recuperar, con una visión crítica, las plataformas públicas o privadas para la circulación del conocimiento, los mecanismos y espacios de promoción y sociabilidad del conocimiento, y por supuesto, la innovación de la práctica científica, que involucra a distintos actores sociales y poderes políticos y económicos, en el desarrollo de las ciencias en México. 